\title{
Bronchial hyperresponsiveness and analysis of induced sputum cells in Crohn's disease
}

R.M. Bartholo ${ }^{2}$, C. Zaltman ${ }^{1}$, C. Elia ${ }^{1}$, A.P. Cardoso ${ }^{2}$, V. Flores², P. Lago ${ }^{2}$, L. Cassabian², F. Carvalho Dorileo ${ }^{2}$ and J.R. Lapa-e-Silva ${ }^{2}$
Disciplinas de ${ }^{1}$ Gastroenterologia and ${ }^{2}$ Pneumologia, Departamento de Clínica Médica, Hospital Universitário Clementino Fraga Filho, Instituto de Doenças do Tórax, Universidade Federal do Rio de Janeiro, Rio de Janeiro, RJ, Brasil

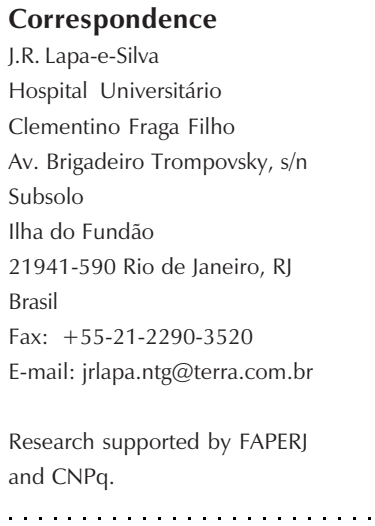

Received January 22, 2004 Accepted December 9, 2004

\begin{abstract}
With the aim of investigating the presence of latent inflammatory process in the lungs of patients with Crohn's disease, 15 patients with Crohn's disease were evaluated by spirometry, the methacholine challenge test, induced sputum, and skin tests for inhaled antigens. Serum IgE, erythrocyte sedimentation rate and hematocrit were also determined. The patients were compared with 20 healthy controls by the Mann-Whitney and Fisher exact tests. Their respiratory physical examination was normal. None had a personal or family history of clinical atopy. None had a previous history of pulmonary disease, smoking or toxic bronchopulmonary exposure. None had sinusitis, migraine, diabetes mellitus, or cardiac failure. Four (26.6\%) of the patients with Crohn's disease had a positive methacholine challenge test whereas none of the 20 controls had a positive methacholine test $(\mathrm{P}=0.026$, Fisher exact test). Patients with Crohn's disease had a higher level of lymphocytes in induced sputum than controls (mean 14.59\%, range 3.2-50 vs $5.46 \%, 0-26.92 \%$, respectively; $\mathrm{P}=0.011$, Mann-Whitney test). Patients with Crohn's disease and a positive methacholine challenge test had an even higher percentage of lymphocytes in induced sputum compared with patients with Crohn's disease and a negative methacholine test (mean 24.88\%, range 12.87-50 vs $10.48 \%$, 3.2-21.69\%; $\mathrm{P}=0.047$, Mann-Whitney test). The simultaneous findings of bronchopulmonary lymphocytosis and bronchial hyperresponsiveness in patients with Crohn's disease were not reported up to now. These results suggest that patients with Crohn's disease present a subclinical inflammatory process despite the absence of pulmonary symptoms.
\end{abstract}

\section{Introduction}

Many extraintestinal manifestations affecting various organs or organ systems have been described in association with in-
Key words

- Inflammatory bowel disease - Crohn's disease

- Bronchial hyperresponsiveness

- Lymphocytosis 
obliterans with organizing pneumonia, pleuropericarditis (1), recurrent pulmonary edema (3), granulomatous (4,5) and nongranulomatous interstitial pulmonary disease (6), granulomatous lung masses (7), bronchiectasis (8), and granulomatous bronchiolitis (9). Tracheal involvement in Crohn's disease is even more unusual and consists of mucosal inflammation (10-12). Drug therapy is another complicating factor, since sulfasalazine used in the treatment of Crohn's disease can also cause reactions in the lung (13-15).

Crohn's disease should be regarded as a multisystemic disorder that involves mainly the gastrointestinal tract. Although the overall prevalence of concomitant bronchopulmonary manifestations is only $0.4 \%$ (16), subclinical alterations in at least half of the adults with Crohn's disease have been demonstrated $(17,18)$ suggesting underlying bronchial inflammation. This pulmonary involvement can be reflected by an increased lymphocyte count in the bronchoalveolar lavage fluid $(19,20)$ and/or lung function abnormalities $(21,22)$.

Latent pulmonary involvement has been reported in a pediatric population with Crohn's disease, despite a short duration of the disease and absence of smoking (22). An increased bronchial hyperresponsiveness in patients with inflammatory bowel disease with no bronchopulmonary symptoms and with normal baseline lung function has been reported (23). Recently, Mansi et al. (24) reported bronchial hyperresponsiveness to methacholine in children with Crohn's disease with no evidence of airway disease.

Recent studies have suggested that the common mucosal immune system may be involved in various T-lymphocyte-mediated disorders. An increased frequency of asymptomatic bronchial hyperresponsiveness has been reported in patients with Crohn's disease, and a subclinical accumulation of activated T lymphocytes has been demonstrated in the lung of patients with Crohn's disease without respiratory symptoms $(19,25)$. No study has demonstrated thus far the simultaneous presence of alveolar lymphocytosis and bronchial hyperresponsiveness to methacholine in respiratory asymptomatic patients with Crohn's disease. In the present study, we compared bronchial responsiveness to methacholine and cellularity of the sputum of patients with Crohn's disease and healthy controls.

\section{Subjects and Methods}

\section{Subjects}

The patients were recruited at the outpatient Gastroenterology clinic of the Clementino Fraga Filho University Hospital and Cardoso Fontes Municipal Hospital, Rio de Janeiro, RJ, Brazil. Fifteen patients with Crohn's disease were included, comprising 7 females and 8 males, 18 to 53 years of age (mean 33.93). The following confounding conditions were excluded: a history of clinical manifestations of atopy, cigarette smoking, a previous history of pulmonary disease, bronchopulmonary exposure to toxic chemicals or fumes, sinusitis, associated diseases such as diabetes mellitus, cardiac failure, migraine or cystic fibrosis, and a family history of asthma. Physical examination and chest radiographs were normal. Baseline pulmonary function was normal. The diagnosis of Crohn's disease was made by internationally recognized and accepted criteria (26). Duration of Crohn's disease at the onset of the study ranged from 6 months to 30 years (mean duration 8.3 years). Three patients had systemic manifestations such as arthralgias and one had sacroileitis. Crohn's disease activity was measured by the HarveyBradshaw index (27). One patient had active disease (Bradshaw index $=7$ ). Thirteen patients were treated with prednisone (12.5 to $40 \mathrm{mg} /$ day) and 2 patients were treated with budesonide (enema). Associated drugs were metronidazole (3 patients), sulfasalazine (2 patients) and mesalazine (2 patients). 
The control group consisted of 20 healthy volunteers, 12 females and 8 males ranging in age from 17 to 55 years (mean 27.6). None were cigarette smokers or had a personal or family history of asthma or atopy. Physical examination and chest radiographs were normal. Baseline pulmonary function was normal.

All patients and control subjects agreed to take part in the study and signed an informed consent form. The University Hospital Ethics Committee approved the study.

\section{Atopy}

Atopy was evaluated by skin prick tests for the following aeroallergens: Dermatophagoides pteronyssinus, Dermatophagoides farinae, Blomia tropicalis, and Aspergillus fumigatus, compared with histamine as positive control, and the diluent as negative control. The tests were considered positive when they induced a weal equal to or larger than $3 \mathrm{~mm}$. No differences were observed between healthy controls and patients.

\section{Blood tests}

Erythrocyte sedimentation rate (Westergren method), serum IgE (nephelometry method) and hematocrit were determined to compare the two groups.

\section{Bronchial responsiveness}

Bronchial responsiveness was measured in the morning by methacholine stimulation. Methacholine bromide solutions (Sigma, St. Louis, MO, USA) were dissolved in $0.9 \%$ physiologic saline, stored at $4^{\circ} \mathrm{C}$, and used within days of preparation. The vials were removed from the refrigerator $30 \mathrm{~min}$ before testing. Nose clips were used to prevent dilution of the inhaled solution with air through the nose during slow inhalation. The aerosols were delivered by a dosimeter (Spira Elektro 4; Hengityshoitokefkuf, Helsinki, Finland).
The nebulizer was used with an output of 9 $\mu l$ per $0.6 \mathrm{~s}$ (total delivery of $0.045 \mathrm{ml}$ ). After measurement of forced expiratory volume in $1 \mathrm{~s}$ (FEV1), subjects inhaled an aerosolized physiologic saline solution. FEV1 was measured again after saline inhalation and the value obtained was considered to be the control value. Provided this FEV1 value had not fallen to less than $95 \%$ of the baseline value, a methacholine challenge was carried out. Subjects successively inhaled a methacholine solution of $0.075,0.15,0.31,0.62,1.25$, 2.5, 5.0, 10.0, and $20.0 \mathrm{mg} / \mathrm{ml}$ and FEV1 was measured 30 and $90 \mathrm{~s}$ after each concentration using a Collins GS spirometer (Louisville, CO, USA). The test was stopped when FEV1 fell to less than $80 \%$ of the control value recorded. In this case, the provocative dose of methacholine producing a 20\% fall in FEV1 (PD20) was read from the log-response curve by linear interpolation. Bronchial hyperresponsiveness was defined as a methacholine PD20 of less than 7.80 $\mu \mathrm{mol}$ according to the European standardization for bronchoprovocation tests (28).

\section{Induced sputum}

Sputum was induced by the method of Pin et al. (29). The patients were pretreated with $200 \mu \mathrm{g}$ inhaled salbutamol to inhibit airway constriction and an aerosol of hypertonic saline was then inhaled from an ultrasonic nebulizer. The concentrations of saline were 3,4 , and $5 \%$, and the duration of inhalation was $7 \mathrm{~min}$ for each concentration. After each period of inhalation, the patient was asked to blow his nose, rinse his mouth, and swallow water to minimize contamination with postnasal dripping and saliva, and peak flow was measured in order to record any possible fall in this parameter. The patient was asked to expectorate sputum into a container. If peak flow fell $10 \%$ or more, inhalations were discontinued to prevent severe bronchoconstriction.

The expectoration was processed as soon 
as possible and within $2 \mathrm{~h}$. Sputum was considered adequate when it presented dense and viscid portions that macroscopically appeared to be free of salivary contamination. These portions were selected and placed in a 15-ml polystyrene tube (Falcon 2097 Becton Dickinson, Franklin Lakes, NJ, USA). The selected portion was treated with dithiothreitol (Sigma) diluted to $0.1 \%$ by the addition of distilled water to dissociate the disulfide bonds of the mucus. The mixture was vortexed for $15 \mathrm{~s}$ and gently aspirated in and out of a Pasteur pipette to ensure mixing. The polystyrene tube was rocked for $15 \mathrm{~min}$ in a bench rocker. Then, 4 additional volumes of phosphate-buffered saline were added to stop the effect of dithiothreitol on the cell suspension and the rocking was continued for $5 \mathrm{~min}$. The suspension was centrifuged and the supernatant was aspirated and stored in 1.5-ml Eppendorf tubes (National Scientific Supply Co., San Rafael, CA, USA) at $-70^{\circ} \mathrm{C}$ for later examination of fluid-phase components.

The cell pellet was resuspended in $1 \mathrm{ml}$ PBS and a total leukocyte count was performed with hemocytometer. Cell viability was determined by Trypan blue exclusion and the total and absolute numbers of cells of processed sputum were calculated. The cell suspension was adjusted to $1.0 \times 10^{6} / \mathrm{ml}$ and cytospins were prepared (Cytospin 3 Shandon; Astmoor, Runcorn, England). Slides were airdried and stained with the Diff-Quick stain (Laborclin, Pinhais, PA,
Brazil) and differential cell counts of at least 200 nonsquamous cells were performed.

\section{Statistical analysis}

The Mann-Whitney test was used for comparison between patients and controls, and the Fisher exact test was used when an expected value was less than 5 . The level of significance was set at $\mathrm{P} \leq 0.05$ in all analysis. The statistical package Epi-Info 6 was used for calculations.

\section{Results}

\section{Bronchial responsiveness}

Fifteen patients with Crohn's disease without respiratory symptoms and 20 healthy controls participated in the study. Four patients with Crohn's disease $(26.7 \%)$ had a positive methacholine challenge indicating bronchial hyperresponsiveness. The measurements of PD20 in these patients were $1.85,6.08,7.48$, and $7.48 \mu \mathrm{mol}$. The other 11 Crohn's disease patients and the 20 healthy controls had negative a methacholine challenge, i.e., with PD20 above the cut-off point of $7.80 \mu \mathrm{mol}(\mathrm{P}=0.026$, Fisher exact test $)$.

\section{Induced sputum}

Of the 15 patients with Crohn's disease who participated in the study, one did not produce adequate induced sputum, as de-

Table 1. Differential cell counts of induced sputum in Crohn's patients and healthy controls.

\begin{tabular}{lcccc}
\hline Group & \multicolumn{4}{c}{ Cell counts } \\
\cline { 2 - 5 } & $\begin{array}{c}\text { \% Lymphocytes } \\
\text { (range) }\end{array}$ & $\begin{array}{c}\% \text { Macrophages } \\
\text { (range) }\end{array}$ & $\begin{array}{c}\% \begin{array}{c}\text { Eosinophils } \\
\text { (range) }\end{array} \\
\text { Crohn's disease }(\mathrm{N}=15)\end{array}$ & $\begin{array}{c}\text { \% Neutrophils } \\
\text { (range) }\end{array}$ \\
\hline Control $(\mathrm{N}=20)$ & 14.59 & 72.33 & 0 & 3.77 \\
& $(3.20-50.00)$ & $(45.31-82.35)$ & & $(0-13.04)$ \\
& 5.46 & 79.80 & 0.13 & 6.33 \\
& $(0-26.92)$ & $(54.28-100)$ & $(0-0.94)$ & $(0-37.14)$ \\
\hline
\end{tabular}

${ }^{*} \mathrm{P}<0.05$ compared to control (Mann-Whitney test). 
fined above. The lymphocyte counts for these patients were significantly higher than for the control group (Table 1). Differential counts of induced sputum were not statistically different concerning other cell types. Patients with Crohn's disease and a positive methacholine challenge test had an even higher percentage of lymphocytes in induced sputum compared with other Crohn's disease patients but a negative methacholine test (mean $24.88 \%$, range $12.87-50$ vs $10.48 \%$, 3.2-21.69\%; $\mathrm{P}=0.047$, Mann-Whitney).

\section{Discussion}

The results of the present study demonstrated that bronchial hyperresponsiveness occurs in a high proportion $(26.7 \%$ ) of adult patients with Crohn's disease compared to $0 \%$ of normal healthy controls. The PD20 values found in these patients, however, were higher than most of those seen in asthmatic individuals (30). This condition was observed despite the absence of clinical, radiological and functional evidence of airway disease, in agreement with data reported by Louis et al. (23) who observed bronchial hyperresponsiveness in $45 \%$ of the patients with intestinal bowel disease, including patients with ulcerative colitis. In 2000, Mansi et al. (24) reported bronchial hyperresponsiveness in $71 \%$ of children and adolescents with Crohn's disease.

Bronchial hyperresponsiveness is a phenomenon related to multiple factors, including inflammation of the airways by several inflammatory cell types and their products, epithelial damage, microvascular leakage, and autonomic neural mechanisms. Conditions other than asthma can be associated with a positive pharmacologic challenge with methacholine or other agonists, such as allergic rhinitis, bronchiectasis, chronic obstructive pulmonary disease, cystic fibrosis, hypersensitivity pneumonitis, left ventricular failure, lung and heart-lung transplantation, sarcoidosis, tropical pulmonary eosinophilia, viral upper or lower respiratory tract infection within 6 weeks of testing, and rarely in normal subjects (31). The cut-off point of $7.8 \mu \mathrm{m}$ for bronchial hyperresponsiveness used in this study was initially established by Woolcock et al. (32) in 1983 for the cumulative test using histamine and confirmed in a subsequent study (33) using methacholine. This value was maintained in the 1993 European standardization (28) and is used by most laboratories.

The present study revealed an increased percentage of lymphocytes in the differential counts of induced sputum in patients with Crohn's disease compared with normal controls. Wallaert et al. (19) reported a high proportion of increased alveolar lymphocytosis in patients with Crohn's disease free of clinical symptoms and with normal chest roentgenograms. The significance of the increased percentage of lymphocytes is not clear. It is currently admitted that a part of the immune system specific to the gastrointestinal tract is common to all mucosal surfaces (34). Therefore, the association of Crohn's disease and lymphocyte alveolitis might be the result of an immunologic mechanism. The lymphocytes sensitized to antigens at one mucosal site could circulate and populate the mucosal surfaces of the lung (19). Muller et al. (34) showed that CD4 were vigorously activated in the intestinal mucosa of patients with active Crohn's disease.

The proportion of lymphocytes in the induced sputum of patients with Crohn's disease and a positive methacholine challenge was higher than in patients with Crohn's disease and a negative methacholine challenge. This fact might represent the existence of a minimum inflammation level from which the methacholine challenge would become positive.

Despite the fact that two patients with a positive bronchoprovocation challenge were using sulfasalazine, a drug reaction was not probable. This would have resulted in an increased number of eosinophils in the induced 
sputum or eosinophilia, which we did not observe. Another aspect was the presence of an interstitial infiltrate which was not found.

There is increasing evidence that subclinical Crohn's disease-associated respira- tory alterations can represent a problem in this group of patients. It is important to be alert to this clinical disorder and to try to detect it as early as possible in order to prevent future respiratory disturbances.

\section{References}

1. Camus P, Piard F, Ashcroft T, Gal AA \& Colby TV (1993). The lung in inflammatory bowel disease. Medicine, 72: 151-183.

2. Rankin GB, Watts D, Melnyc CS \& Kelley ML (1979). National cooperative Crohn's disease study: extraintestinal manifestations and perianal complications. Gastroenterology, 77: 914-920.

3. Bradshaw MJ, Harvey RF \& Burns-Cox CJ (1981). Crohn's disease presenting as recurrent pulmonary edema. British Medical Journal, 2: 1437-1438.

4. McCormick PA, O'Donoghue DP \& Fitzgerald MX (1986). Crohn's colitis and sarcoidosis. Postgraduate Medicine, 62: 951-953.

5. Calder CJ, Lacy D, Raafat F, Weller PH \& Booth IW (1993). Crohn's disease with pulmonary involvement in a 3 year old boy. Gut, 34: 1636-1638.

6. Hotermans G, Benard A, Guenanen H, Demarcq-Delerue G, Malart T \& Wallaert B (1996). Nongranulomatous interstitial lung disease in Crohn's disease. European Respiratory Journal, 9: 380-382.

7. Lucero PF, Frey WC, Shaffer RT \& Morris MJ (2001). Granulomatous lung masses in an elderly patient with inactive Crohn's disease. Inflammatory Bowel Diseases, 7: 256-259.

8. Kraft SC (1976). Unexplained bronchopulmonary disease with inflammatory bowel disease. Archives of Internal Medicine, 136: 454-459.

9. Vandenplas $O$, Casel S, Delos M, Trigaux JP, Melange M \& Marchand E (1998). Granulomatous bronchiolitis associated with Crohn's disease. American Journal of Respiratory and Critical Care Medicine, 158: 1676-1679.

10. Kuzniar T, Sleiman C, Brugiere O, Groussard H, Mal H, Mellot F, Pariente R, Malolepszy J \& Fournier M (2000). Severe tracheobronchial stenosis in a patient with Crohn's disease. European Respiratory Journal, 15: 209-212.

11. Lemann M, Messing B, D'Agay F \& Modigliani R (1987). Crohn's disease with respiratory tract involvement. Gut, 28: 1669-1672.

12. Lamblin C, Copin MC, Billaut C, Marti R, Tacq V, Riviere O \& Wallaert B (1996). Acute respiratory failure due to tracheobronchial involvement in Crohn's disease. European Respiratory Journal, 9: 2176-2178.

13. Davies D \& MacFarlane A (1974). Fibrosing alveolitis and treatment with sulfasalazine. Gut, 15: 185-188.

14. Salerno SM, Ormseth EJ, Roth BJ, Meyer CA, Christensen ED \& Dillard TA (1996). Sulfasalazine pulmonary toxicity in ulcerative colitis mimicking clinical features of Wegener's granulomatosis. Chest, 110: 556-559.

15. Jones GR \& Malone DNS (1972). Sulfasalazine induced lung disease. Thorax, 27: 713-717.

16. Valletta E, Bertini M, Sette L, Braggion C, Pradal U \& Zannoni M (2001). Early bronchopulmonary involvement in Crohn's disease: a case report. BMC Gastroenterology, 1: 13-18.

17. Bonniere $P$, Wallaert $B$, Cortot $A$, Marchandise $X$, Riou $Y$, Tonnel
AB, Colombel JF, Voisin C \& Paris JC (1986). Latent pulmonary involvement in Crohn's disease: biological, functional, bronchoalveolar lavage and scintigraphic studies. Gut, 27: 919-925.

18. Fireman Z, Osipov A, Kivity S, Kopelman Y, Sternberg A, Lazarov E \& Fireman E (2000). The use of induced sputum in the assessment of pulmonary involvement in Crohn's disease. American Journal of Gastroenterology, 95: 730-734.

19. Wallaert B, Colombel JF, Tonnel AB, Bonniere P, Cortot A, Paris JC \& Voisin C (1985). Evidence of lymphocyte alveolitis in Crohn's disease. Chest, 87: 363-367.

20. Smiejan JM, Cosnes J, Chollet-Martin S, Soler P, Basset FM, Le Quintrec Y \& Hance AJ (1986). Sarcoid-like lymphocytosis of the lower respiratory tract in patients with active Crohn's disease. Annals of Internal Medicine, 104: 17-21.

21. Heatley RV, Thomas P, Prokipchuk EJ, Gauldie J, Sieniewicz DJ \& Bienenstock J (1982). Pulmonary function abnormalities in patients with inflammatory bowel disease. Quarterly Journal of Medicine, 203: 241-250

22. Munck A, Murciano D, Pariente R, Cezard JP \& Navarro J (1995). Latent pulmonary function abnormalities in children with Crohn's disease. European Respiratory Journal, 8: 377-380.

23. Louis E, Louis R, Drion $\mathrm{V}$, Bonnet $\mathrm{V}$, Lamproye A, Radermecker M \& Belaiche $J$ (1995). Increased frequency of bronchial hyperresponsiveness in patients with inflammatory bowel disease. Allergy, 50: 729-733.

24. Mansi A, Cucchiara S, Greco L, Sarnelli P, Pisanti C, Franco MT \& Santamaria $F(2000)$. Bronchial hyperresponsiveness in children and adolescents with Crohn's disease. American Journal of Respiratory and Critical Care Medicine, 161: 1051-1054.

25. Adenis A, Colombel JF, Lecouffe P, Wallaert B, Hecquet B, Marchandise X \& Cortot A (1992). Increased pulmonary and intestinal permeability in Crohn's disease. Gut, 33: 678-682.

26. Bernades $P$, Hecketsweiler P, Benozio M, Descos L, Geffroy $Y$, Hemet J, Loygue J, Modigliani R, Potet F \& Weill JP (1978). Proposition d'un système de critères pour le diagnostic des entérocolites inflammatoires cryptogénétiques (maladie de Crohn et rectocolite hémorragique). Gastroenterologie Clinique et Biologique, 2: 1047-1054.

27. Harvey RF \& Bradshaw JM (1980). A simple index of Crohn'sdisease activity. Lancet, 1: 514.

28. Sterk PJ, Fabbri LM, Quanjer PH, Cockcroft DW, O'Byrne PM, Anderson SD, Juniper EF \& Malo JF (1993). Airway responsiveness. Standardized challenge testing with pharmacological, physical and sensitizing stimuli in adults. Official Statement of the European Respiratory Society. European Respiratory Journal, 16 (Suppl): 53-83

29. Pin I, Gibson PG, Kolendowicz R, Girgis-Gabardo A, Denburg JA, Hargreave FE \& Dolovich J (1992). Use of induced sputum cell 
counts to investigate airway inflammation in asthma. Thorax, 47: 25-29.

30. Cockcroft DW (1985). Bronchial inhalation tests. Measurement of nonallergic bronchial responsiveness. Annals of Allergy, 55: 527534.

31. Irwin RS \& Pratter MR (1990). The clinical value of pharmacologic bronchoprovocation challenge. Medical Clinics of North America, 74: 767-778.

32. Yan K, Salome C \& Woolcock AJ (1983). Rapid method for measurement of bronchial responsiveness. Thorax, 38: 760-765.
33. Peat JK, Salome CM, Bauman A, Toelle BG, Wachinger SL \& Woolcock AJ (1991). Repeatability of histamine bronchial challenge and comparability with methacholine bronchial challenge in a population of Australian school children. American Review of Respiratory Disease, 144: 338-343.

34. Muller S, Lory J \& Corazza N (1998). Activated CD4 and CD8 cytotoxic cells are present in increased numbers in the intestinal mucosa from patients with active inflammatory bowel disease. American Journal of Pathology, 152: 261-268. 